\title{
Erman, Tahire \& Özaloğlu, Serpil. Bir Varmış Bir Yokmuş Toplumsal Bellek, Mekân ve Kimlik Üzerine Araştırmalar. İstanbul: KÜY Yayınları, 2017, 334.sf
}

\section{Sercan EKLEMEZLER *}

Mekân çalışmaları ve bellek çalışmaları, 1960'lardan bu yana benzer bir eğilimle sosyolojiden edebiyata, psikolojiden kent bilimlerine kadar birçok disipline konu olmuştur. Bu süreçte, çeşitli kuramsal bakış açlarının ilgi alanına giren bellek ve mekân, kimliği kuran unsurlar olarak birlikte ele alınmaya başlanmıştır. Erman ve Özaloğlu'nun derledikleri bu çalışma da söz konusu unsurlara ve bu unsurlar arasındaki ilişkiye odaklanmaktadır. Bellek ve mekâna dair çalışmaların çok sayıda disiplinin ortak ilgisi olduğu burada da göze çarpmaktadır, zira yazarlar arasında iki araştırmacı, bir küratör ve üç doktora öğrencisinin dışında çok sayıda akademisyen yer almaktadır. Akademisyenlerin alanlarına bakıldı̆̆ındaysa felsefeden antropolojiye, tarihten dil ve iletişim bilimlerine, siyaset bilimi ve kamu yönetiminden sosyoloji ve sosyal hizmete kadar geniş bir çeșitlilik göze çarpmaktadır. Ancak, şehir ve bölge planlama, iç mimarlık ve çevre tasarımı ile mimarlık gibi mekânı temel alan disiplinlerden akademisyenler (13 akademisyen) bu çalışmanın yazarları arasında çoğunluğu oluşturmaktadır.

Bellek ve mekân ilişkisine odaklanan bu derleme kitap, sekiz bölümden ve 28 makaleden oluşmaktadır. Birinci bölümde genel hatlarıyla bellek, mekân ve tarih ilişkisiyle ilgili kuramsal

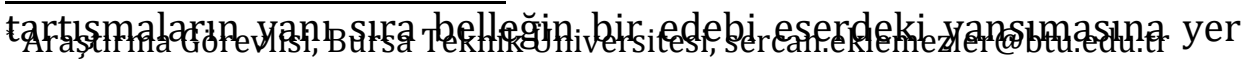
ORCID: 0000-0003-3198-8413 
verilmektedir. İkinci bölüm bellek ve mekân ilişkisini yakın geçmişe ait mekânlar (İkramiye evleri, Büyük Efes Oteli, Petkim-Aliağa konut yerleşkesi gibi) ve bu mekânlarda gerçekleşen dönüşümler üzerinden ele almaktadır. Mekânsal değişme ve dönüşüm konularını ele alan çalışmalar, ikinci bölümden başlayıp, dördüncü bölüme kadar devam etmektedir. Üçüncü ve dördüncü bölüm özellikle kentsel mekânda gerçekleşen ve gecekondu olgusunu da içeren dönüşüm projeleri ve toplumsal yansımalarına eğilmektedir. Beşinci bölüm, özellikle hafıza mekânlarına ayrılmıştır. Altıncı bölüm, toplumsal çeşitlilik vurgusuyla farklı toplumsal grupların mekâna dair deneyimlerine yer verirken Neo-liberal Dönüşümler başlıklı yedinci bölüm, bir anlamda kitabın alt metnini başlığa taşımış durumdadır. Sonuncu bölüm ise mekân, kimlik ve aidiyet konularına eğilmektedir.

\section{Bellek Üzerine Düşünsel Denemeler}

Kitabın ve bu bölümün ilk makalesi, hafıza ve mekân ilişkisine dair kuramsal alt yapıyı sunmaktadır. Bu makalenin ana fikri, yazarın Lefebvre'den alıntıladığı "gündelik yaşamımıza ilişkin her türlü deneyim, mekânı içerir" cümlesinden beslenir. Yazara göre, bellek aynı zamanda bir toplumsal güç/iktidar sorunudur. Çalışmasında yazar ayrıca geçmişin korunamayıp, şimdiki zamana göre yeniden kurgulandığını belirtir. Bu nedenle, tarih ve hatıra arasındaki ilișkide ise anıların tarihin kendisi değil, ancak nesneleri olabileceğini ifade etmektedir (s.19). Özaloğlu'nun değindiği bellek, tarih ve iktidar ilişkisini daha ayrıntılı bir biçimde ele alan Tunçel'e göre (bkz. II. makale), iktidarın edimleri yalnızca bellekte tutulanları değil, aynı zamanda unutulması gerekenleri de belirlediğinden "Belleğin kendisi kurgulanan bir yapıya dönüşmüştür.” (s.23) Yazar, Ricoeur'den hareketle bellek ve iktidar sorunu hakkında bir öneride bulunmaktadır: "Özgürlüğün olanağını gerçekleştirmek için gereken, belleğin ezberini bozma, [...] egemen söylem yüzünden çoğu zaman sözden yoksun bırakılmış; ama tarih aracılığıyla söze kavuşan gündelik yaşamın insanını söze kavuşturma cesaretidir" (s.25). Birinci 
bölümdeki son makalede Kılıçkaya, Mehmet Eroğlu'nun 2006 senesinde yayımladığı Belleğin Kış Uykusu isimli eserini bellek kavramı etrafında incelemektedir. Dolayısıyla birinci bölüm belleğin edebiyattaki yansımalarından birinin üzerinde duran bu yazıyla sona ermektedir.

\section{Kent, Mekân ve Hatırlama/Unutma: Yakın Geçmişimizden Bugüne Dönüşüm}

Mekânsal değişim ve dönüşümlerin toplumsal hafizayla ilişkisini ele alan bu bölüm üçüncü ve dördüncü bölümün aksine, mekânsal dönüşüm olgusunu gecekondu ve kentsel dönüşüm ikilisinin dışında tartışmaktadır. Rouen yazısında, 1945-60 yılları arasındaki TeşvikiyeNişantaşı'nı mekânsal açıdan ele almaktadır. Makale "apartman yaşamı" bağlamında geleneksel aileden çekirdek aileye geçişi irdelemektedir. Demokrat Parti'nin “çekirdek aile”yi destekleyici politikalarına karşın bu yeni ortamda geleneksel geniş ailenin sürdürüldüğü, makalenin çarpıcı tespitidir (s.33). Rouen 1945 ile 1960 yılları arasında Nişantaşı'nda gerçekleşen mekânsal dönüşümü ve buna karşın toplumsal yaşamdaki dönüşümün hızının mekânsala göre daha yavaş gerçekleştiğini ileri sürerken Şumnu da (bkz. V. makale) tarih aralığı olarak çokça farklılaşmayan bir dönemi incelemektedir. 1940 ile 1970 yılları arasında Türkiye'de konut kültürünün oluşmasında önemli bir üretim olarak karşımıza çıkan ikramiye evleri Şumnu'nun yazısında ele alınmaktadır. 1975 yılında ise bankaların ikramiyelerini kaldıran bir karar alınmıștır. Çalışmada ortaya konduğu üzere, tasarruf alışkanlığının yaygınlaştırılması isteğinden liberal politikaların benimsenmesi ile vazgeçilmesi, bu kararın gerekçesidir. Konut politikaları ve makro sosyoekonomik değişimlerin ilişkisi ise bu makalenin başlıca kuramsal dayanağıdır (s.57). Diğer bir makalede Yllmaz ve İnceköse ise daha spesifik olarak tek bir simgesel yapı ve kent hafızası ilişkisine odaklanmışlardır. Efes Otelinin, inşa süreci ve sonrasında İzmirlilerin hafızalarında nasıl bir 
karşılık bulduğu, bu makalenin konusudur. Uzun yıllar fiziksel varlığıyla ön plana çıkan Efes Otelinin, bugün küresel sermayenin temsil ettiği bir isimle (bir marka olarak) öne çıkıyor olması, makalenin başlıca tespiti olmanın yanında neoliberal değişimlerin mekândaki yansımasının vurgulanması itibariyle diğer makalelerle ortaklaşan yönüdür (s.75). Korkmaz'ın çalışmasında 1975-78 arasında planlanan ve 1984'e kadar inşa edilen Petkim-Aliağa Konut Yerleşkesi KíT'lerin ve toplumsal bellekte yer edinen iş yerinde barınma pratiğinin son örneği olarak ele alınmıştır. Planlama ve inşası devletçi ekonomiden vazgeçilen ve neoliberal dönüşümlerin yaşandığı bir döneme rast gelse de cumhuriyetçi kentsel gelişme ideallerinin devam ettirildiğinin bir örneği olarak bu makalede konu alınan Petkim-Aliağa Konut Yerleşkesi dikkate değerdir.

\section{Kentsel/Kırsal Müdahaleler ve Mekândan Silinme}

$\mathrm{Bu}$ bölümde kentsel mekânda gerçekleşen değişimler ele alınmıştır. Artvin-Çoruh Vadisi'ndeki HES'lerin çevre köylerde sebep olduğu yok oluşlar, ilk makalenin başlıca konusudur. Belleğin, insanın tarihinin bilgi deposu olduğu iddiası ise bu makalenin tartışmalı noktasıdır (s.87). Augustinus, hafıza ve mekân ilişkisine, "kiler", "depo" gibi bir dizi görsel mecazla birlikte değinmiştir (akt. Ricoeur, 2012, 117). Ancak, Augustinus'un ve bu makalenin yazarlarının "bellek" ve "depo" arasında kurduğu analojinin ötesinde Özaloğlu (s.18) ile Özmen ve Çetin'in (s.107) de ifade ettikleri gibi, bellek daha canlı, dinamik ve bugünden geriye doğru yeniden kurgulanan bir olgu olarak ele alınır olmuştur. Bu bölümde yer alan diğer iki makalenin konusu da kentsel dönüşüm çalışmalarıdır. Bunlardan, Çetken'in kaleme aldığı çalışma, Memento ve Eternal Sunshine of the Spotless Mind filmleri üzerinden hafızanın kaybolduğu ortamda yaşananlar ve kentsel dönüşüm pratikleri arasında bir ilişki kurmaktadır. Çalışmanın değindiği 1980’ler ve neoliberal dönüşüm konusu, bu makalenin kitaptaki diğer birçok makale ile benzerlik gösteren noktasıdır (s.94). Çalışmalarında kentsel mekâna dair bir başka "yeni" 
ve “yenileme" arayıșını ele alan Özmen ve Çetin'e göre, Tarlabaşı Yenileme Projesi yıllar boyunca birikerek gelmiş olan belleği geri dönülemez şekilde yeniden kurgulamaya yöneliktir. Dahası yazarların da üzerinde durduğu gibi bu proje yaratmak istediği yeni toplumsal sınıfla beraber tarihi çevreyi bir dekor olarak kullanmaktadır (s.107).

\section{4. "Bir Varmış Bir Yokmuş Gecekondu": Gecekondu Dönüşüm Projeleri Masal Değildir}

Bu bölüm özellikle "gecekondu" olgusuna eğilen dört makaleden oluşmaktadır. İlk çalışmada, belleklerde kalan gecekondu araştırılmaktadır. Aktaş Mahallesi örneğinden hareketle kaleme alınan ikinci çalışmada, yoksul kadınların gündelik yaşamlarında gecekondu dönüşüm projesiyle meydana gelen değişimler aktarılmaktadır. Neoliberal politikaların yönetsel olarak da benimsenmesi, bölümün üçüncü makalesinde ele alınan Küçükçekmece Ayazma mevkiindeki kentsel dönüşüm için bir meşruiyet zemini oluşturmuştur. Bu projenin diğer kentsel dönüşüm projelerinden ayırt edici yönü, "sosyo-ekonomik çöküntü bölgesi" olarak nitelendirilen Ayazma'da yaşayan Kürt nüfusun “ötekiler” olarak nitelendirilmesi ve yeniden iskân edildikleri yerde karşılaştıkları problemlerdir (s.138-145). Bölümde yer alan son çalışmanın iddiası ise, kentsel dönüşümün var olanı sağlıklaştırmak yerine tamamen yıkmak üzerine olduğu ve bu olgu üzerinden rant elde edilmenin amaçlandığıdır (s.148).

\section{Kentin "Hafiza Depoları"}

Bu bölümün Nora (2006) tarafından kavramsallaştırılan "hafıza mekânları"na ayrıldığı görülmektedir. Keskin'in kaleme aldığı makalede (bkz. XV. makale), Diyarbakır Kent Müzesi, bir "hafıza mekânı” olarak ele alınmaktadır (s.155-161). Çalışmanın temel iddiası, genel olarak hafıza mekânlarının özel olarak da müzelerin birinci işlevinin ideolojik olduğudur. Yazara göre, Diyarbakır Kent 
Müzesi, bu ideolojik işlevini, mekân seçiminden başlayarak yerine getirmektedir. Balkanay ise "Kolektif Belleğin Yeniden İnşası: Ulucanlar Cezaevi Müzesi'nde Özne-Mekân İlişkisi” isimli çalışmasında, biyoiktidar kuramlarından azca etkilenerek kavramsal çerçevesini oluşturmuştur. Bu çalışma da iktidar, ideoloji ve mekân kavramları etrafında şekillenmiştir. Yazar, Ulucanlar Cezaevi'nin, hem şiddetin hem de direnişin mekânı olduğunu öne sürmektedir (s.165). Ona göre, müzeleştirilen mekân, izletilen objelerin birer gösteri nesnesine dönüştügü ve aura'sını kaybettiği bir yer haline gelmiştir. Ancak, müze ve müzenin temsil potansiyeli birçok başka çalışmanın konusu olabilecek niteliktedir. Bölümün son çalışması ise "hafıza mekânı" kavramının içeriğinin genişliğine uygun düşen şekilde, müzeler dışında bir mekâna (mezarlıklara) eğilen yanıyla farklılaşmaktadır. Yazar, burada Anadolu'daki cemaatler arasındaki ilişkileri, mezarlıklar üzerinden anlamaya çalışmaktadır. Çalışma, Gayrimüslim-Müslüman ikiliğinden farklılaşarak, aynı dinsel yapılar içindeki farklı etnisite ve mezheplere eğilmesi ile de dikkat çekmektedir.

\section{Toplumsal Çeşitlilik İçin Hatırla(t)ma}

$\mathrm{Bu}$ bölümde yer alan dört çalışmadan ilki Alevilere, ikincisi Yezidilere, üçüncüsü mübadillere ve dördüncüsü önceden farklı toplumsal grupların bir arada yaşadığı bir mekâna (Yayla Mahallesi) odaklanmaktadır. Kısacası bu bölüm farklı toplumsal grupların hafıza ve mekânla ilişkisine eğilmektedir. İlk makalede kısaca, ocak kavramı ve Aleviliğe dair kültürel pratikler, bellek aktarımı açısından irdelenmektedir. İkinci çalışmada Cengiz, Yaşar Kemal'in Bir Ada Hikâyesi dörtlemesi üzerinden Yezidiler'in öyküsünü değerlendirmektedir (s.193-198). Karakılıç'ın kaleme aldığı çalışmanın temel iddiası ise, "hem mübadeleden önce Yunanistan'da, hem de mübadeleden sonra Türkiye'de tütün ticareti ve tarımı ile geçinen insanların mübadele çevresinde şekillenen hatıralarını tütün tarımı pratikleri üzerinden paylaşıp sonraki kuşaklara 
aktarabildikleridir." (s.199-209). Üretim pratikleri ve toplumsal hafiza ilişkisini ele alması bakımından makale dikkate değerdir.

\section{Neoliberal Dönüşümler}

$\mathrm{Bu}$ bölüm kitabın tümündeki ortak izleği yani neoliberal dönüşümlerin mekândaki ve toplumsal bellekteki etkilerinin araştırılmasını doğrudan başlı̆ı̆na taşımıştır. Önkal'a göre (bkz. XXII. makale) butik kimliklerin ortaya çıkması söz konusu neoliberal değişimlerin sonuçlarından birisidir. Bölümün ikinci çalışmasındaysa yazarlar, neoliberal belleğin "şimdi"ye sıkıştırılmasını ve belleğin metalaşmasını ele almaktadır. Bu çalışmada da "Kolektif Belleğin Yeniden İnşası: Ulucanlar Cezaevi Müzesi'nde Özne-Mekân İlişsisi" makalesi gibi iktidar ilişkileri ele alınırken biyopolitika kavramlarından faydalanmıştır (s.229-239). Bölümün üçüncü makalesinde Yardımcı, ODTÜ'de çalışan taşeron temizlik işçileri ile görüşmeler gerçekleștirerek, neoliberal dönüşümle birlikte sınıf ilişkilerindeki değişimi anlamaya çalışmaktadır. Can Gündüz tarafından kaleme alınan çalışma ise neoliberal dönüşümlerin mekândaki yansımasına karşı bir direniş mekânının imkânını tartışmaktadır. Ancak, yazar Seferihisar örneği üzerinden ele aldığı Cittaslow modelinin gerçekleştirilen fuarlar, kongreler gibi etkinliklerle neoliberal kapitalizme eklemlendiğini ileri sürerek bir direniş mekânına dair umutsuzlukla yazısını noktalamaktadır (s.265).

\section{8. Öncesi ve Sonrasıyla 1980 Darbesi: Temsiliyet ve Hatırlama}

Son bölüm kitabın başlı̆ı̆ında yer alan üç kavram (toplumsal bellek, mekân ve kimlik) arasındaki ilişkiyi ele alan çalışmalardan oluşmaktadır. Çavuş çalışmasında ülkenin yakın tarihini işleyen dört popüler film üzerinden toplumsal belleğin inşasını ele almıştır. Yazar, aynı zamanda filmlerin 12 Eylül dönemini aktarışlarına odaklanmaktadır. Çavuş sinemaya odaklanırken Vural ise edebiyatı ele aldığı, çalışmasında 1983-2010 arasında yayımlanan 32 
romandaki temsilleri çözümleyerek, 78 kuşağı bağlamında kuşakbellek ve tecrübe ilişkisini incelemiştir. Yazar, 78 kuşağı içinde toplumsal cinsiyetin yerini irdelemiş ve bu kuşak içerisinde kadının, bir kadın kimliğinden ziyade kolektif bir yapının parçası olarak var olabildiği sonucuna ulaşmıştır. Önce Çocuklar Öldü romanındaki Mukaddes karakterinin 78 kuşağına ait yatkınlıklarını kadın hareketi ile birleştirmeyi başarabilmesi, diğer kuşak üyeleri tarafından genellikle benimsenmeyen bir aykırı durum olarak çarpıcıdır (s.290). Kitabın son çalışması, "mekân ve aidiyet ilişkisine "ev" üzerinden yaklaşmaktadır. Bu çalışma dışında bellek ve mekân ilişkisini kuran başka bazı çalışmalar da (örn., Dovey, 1985; Öymen Özak ve Pulat Gökmen, 2009), "ev" mekânı üzerine yoğunlaşmıştır. Etnografik yöntemle yürüttüğü çalışmasını Kılıçkıran, Bourdieu'nun habitus kavramı ve Massey'in mekân ve yer kavramları üzerine kurmuştur. Yazarın iddiası, evin mülteci Kürt kadınlar tarafından göçün yarattığı kayıp ve kopma hissine karşı bir kimlik ve direniş mekânı olarak kurulduğudur.

\section{Sonuç}

Mekânla birlikte toplumsal bellek ve kimlik gibi sosyal bilimlerin konusu olan olguların irdelendiği bu çalışma, mekânı konu alan disiplinlerden gelen yazarların ekseriyetinde yapılandırılmıştır. $\mathrm{Bu}$ çalışmanın ekseni, ekonomi-politikte meydana gelen neoliberal dönüşümlerin mekâna ve toplumsal yapıya olan etkisi ve bu etkinin incelenmesidir. $\mathrm{Bu}$ derlemedeki makaleler göstermektedir ki, makroekonomik değişiklikler, aynı hızda olmasa da mekânı ve toplumsal yapıyı doğrudan etkilemektedir.

İktidarın bellek üzerindeki gücü, derlemedeki birçok makalenin odaklandığı mevzudur. Bu güce karşın direniş imkânının gündelik yaşamdaki insana söz hakkı tanımaktan geçtiği ifade edilmektedir. Bahse konu olan iddia ise sözde kalmayıp çok sayıda sözlü tarih çalışması, derinlemesine görüşme gibi birçok çalışmayla da pratiğe 
dökülmüștür. Neoliberal dönemde toplumsal belleğin şu ana sıkıştırılmış olması ve bir meta haline gelmesi de çalışmanın çarpıcı iddialarından birisini oluşturmaktadır. Sonuç itibariyle 28 farklı makaleyi bir araya getiren bu çalışma, mekân ve bellek konusuyla ilgilenen çok sayıda disiplin için kaynak niteliği taşımaktadır.

\section{Kaynakça}

Dovey, Kimberly, "Home and Homelessness", Home Environments: Human Behaviour and Environment, haz. I. Altman ve C. Werner, New York: Plenum, 1985.

Nora, Pierre. Hafiza Mekânları, çev. M. Özcan. İstanbul: Dost Kitapevi, 2006.

Öymen Özak, Nilüfer \& Pulat Gökmen, Gülçin, "Bellek ve Mekân İlişkisi Üzerine Bir Model Önerisi”. İtüdergisi/a, 2009, 145-155.

Ricoeur, Paul. Hafiza, Tarih, Unutuş, çev. M. Emin Özcan. İstanbul: Metis Yayınları, 2012. 
Sercan EKLEMEZLER 